\title{
Restoration of E-cadherin expression by selective Cox-2 inhibition and the clinical relevance of the epithelial-to-mesenchymal transition in head and neck squamous cell carcinoma
}

Ryoichi Fujii ${ }^{1 \dagger}$, Yorihisa Imanishi ${ }^{1{ }^{*}+}$, Katsushi Shibata ${ }^{2}$, Nobuya Sakai ${ }^{2}$, Koji Sakamoto $^{3}$, Seiji Shigetomi ${ }^{4}$, Noboru Habu', Kuninori Otsuka', Yoichiro Sato ${ }^{1}$, Yoshihiro Watanabe ${ }^{1}$, Hiroyuki Ozawa ${ }^{5}$, Toshiki Tomita', Kaori Kameyama ${ }^{6}$, Masato Fujii and Kaoru Ogawa' ${ }^{1}$

\begin{abstract}
Background: The epithelial-to-mesenchymal transition (EMT) accompanied by the downregulation of E-cadherin has been thought to promote metastasis. Cyclooxygenase-2 (Cox-2) is presumed to contribute to cancer progression through its multifaceted function, and recently its inverse relationship with E-cadherin was suggested. The aim of the present study was to investigate whether selective Cox-2 inhibitors restore the expression of E-cadherin in head and neck squamous cell carcinoma (HNSCC) cells, and to examine the possible correlations of the expression levels of EMTrelated molecules with clinicopathological factors in HNSCC.
\end{abstract}

Methods: We used quantitative real-time PCR to examine the effects of three selective Cox-2 inhibitors, i.e., celecoxib, NS-398, and SC-791 on the gene expressions of E-cadherin (CDH-1) and its transcriptional repressors (SIP1, Snail, Twist) in the human HNSCC cell lines HSC-2 and HSC-4. To evaluate the changes in E-cadherin expression on the cell surface, we used a flowcytometer and immunofluorescent staining in addition to Western blotting. We evaluated and statistically analyzed the clinicopathological factors and mRNA expressions of $\mathrm{Cox}-2, \mathrm{CDH}-1$ and its repressors in surgical specimens of 40 patients with tongue squamous cell carcinoma (TSCC).

Results: The selective Cox-2 inhibitors upregulated the E-cadherin expression on the cell surface of the HNSCC cells through the downregulation of its transcriptional repressors. The extent of this effect depended on the baseline expression levels of both E-cadherin and Cox-2 in each cell line. A univariate analysis showed that higher Cox-2 mRNA expression ( $p=0.037)$, lower CDH-1 mRNA expression $(p=0.020)$, and advanced T-classification $(p=0.036)$ were significantly correlated with lymph node metastasis in TSCC. A multivariate logistic regression revealed that lower $\mathrm{CDH}-1$ mRNA expression was the independent risk factor affecting lymph node metastasis $(p=0.041)$.

Conclusions: These findings suggest that the appropriately selective administration of certain Cox-2 inhibitors may have an anti-metastatic effect through suppression of the EMT by restoring E-cadherin expression. In addition, the downregulation of $\mathrm{CDH}-1$ resulting from the EMT may be closely involved in lymph node metastasis in TSCC.

Keywords: E-cadherin, Cox-2 inhibition, Head and neck squamous cell carcinoma (HNSCC), Epithelial-to-mesenchymal transition (EMT), Lymph node metastasis

\footnotetext{
* Correspondence: yorihisa@ja2.so-net.ne.jp

${ }^{\dagger}$ Equal contributors

'Department of Otorhinolaryngology-Head and Neck Surgery, Keio University

School of Medicine, 35 Shinanomachi, Shinjuku, Tokyo 160-8582, Japan

Full list of author information is available at the end of the article
}

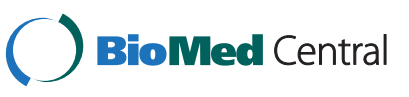

(c) 2014 Fujii et al.; licensee BioMed Central Ltd. This is an Open Access article distributed under the terms of the Creative Commons Attribution License (http://creativecommons.org/licenses/by/4.0), which permits unrestricted use, distribution, and reproduction in any medium, provided the original work is properly credited. The Creative Commons Public Domain Dedication waiver (http://creativecommons.org/publicdomain/zero/1.0/) applies to the data made available in this article, unless otherwise stated. 


\section{Background}

Head and neck squamous cell carcinoma (HNSCC) is the sixth most common cancer with an annual incidence of over 560,000 cases worldwide [1]. Despite various advances in combined modality therapy, the survival rate of HNSCC patients has not improved over the past two decades, due largely to the uncontrollable metastasis to lymph nodes and distant organs [2]. Cervical lymph node metastasis in particular has been considered the most important adverse prognostic factor in HNSCC [3-5]. More effective strategies based on a better understanding of the molecular mechanisms that lead to metastasis are thus indispensable.

Recent progress in tumor biology indicates that the initial steps during the sequential process of metastasis are notably analogous to the epithelial-to-mesenchymal transition (EMT) in which cells lose epithelial features including cell adhesion and gain mesenchymal traits including cell motility during embryogenesis and wound healing $[6,7]$. In the tumor context, the acquisition of the EMT, accompanied by functional loss of E-cadherin that maintains intercellular adhesion, stimulates the dissemination of single tumor cells from primary sites through the loss of cell-to-cell contact, thereby endowing cells with metastatic abilities [6-8]. At the transcriptional level, E-cadherin is downregulated by several transcriptional repressors including snail, slug, DeltaEF1/ZEB1, SIP1 (Smad interacting protein 1)/ZEB2, E12/E47, and twist, by binding to E-box promoter elements of $\mathrm{CDH}-1$, a gene encoding human E-cadherin [6-8]. We recently reported that SIP1 expression was inversely correlated with E-cadherin expression in HNSCC cells, and that the downregulation of E-cadherin and upregulated nuclear localization of SIP1 were independently correlated with delayed neck metastasis in stage I/II tongue squamous cell carcinoma (TSCC) [9]. However, a practical therapeutic approach that leads to the suppression of the EMT has not been developed to control the progression of cancers, including HNSCC.

Cyclooxygenase-2 (Cox-2), an isoform of the Cox enzymes inducible in response to proinflammatory cytokines and growth factors, catalyzes the biosynthesis of prostanoids including prostaglandin $\mathrm{E}_{2}\left(\mathrm{PGE}_{2}\right)$, thereby playing important roles in the regulation of various cellular functions under physiologic and pathologic conditions including carcinogenesis [10-13]. Increased expression of Cox-2 has been found in a variety of human malignancies, including HNSCC [14-16]. Previous studies have reported several mechanisms by which Cox- 2 contributes to carcinogenesis as well as cancer progression, including the activation of carcinogens [17], resistance to apoptosis $[18,19]$, immunosuppression $[20,21]$, the promotion of angiogenesis [11,22], the stimulation of proliferation [23] and invasiveness [24], and the autocrine activity of estrogen [25]. Such a multifaceted function of Cox-2 in conferring the malignant phenotype strongly suggested that Cox-2 is an attractive preventive and therapeutic target for various cancers [12,13,26-29]. A number of clinical trials have been carried out to examine the benefit of Cox-2 inhibitors, such as celecoxib, in the chemoprevention of premalignant lesions such as familial adenoma polyposis (FAP) [30], Barrett's esophagus [31], and oral premalignant lesions [32], as well as in the treatment of advanced cancers in combination with chemotherapy [33-36]. However, these trials could demonstrate neither a significant chemopreventive effect nor any additional therapeutic effect of celecoxib on clinical outcomes, except in FAP, suggesting that the optimal applications of Cox-2 inhibitors should be reconsidered, and that further research is necessary regarding the various mechanisms underlying the anti-cancer effects of Cox-2 inhibitors against tumors.

An inverse relationship between E-cadherin and Cox-2 and its molecular mechanism in cancer cells was first shown in non-small cell lung cancer (NSCLC), in which Cox-2 overexpression led to decreased E-cadherin expression through the upregulation of $\mathrm{PGE}_{2}$ and transcriptional repressors of E-cadherin, whereas the inhibition of Cox-2 showed an inverse regulation of those molecules [37]. A similar effect of Cox-2 inhibitors that reverse the EMT by restoring E-cadherin expression was also found in subsets of colon, gastric, and bladder cancer cells [38-43]. However, in HNSCC, neither the effect of Cox-2 inhibitors on the regulation of E-cadherin expression nor its specific mechanism has been examined to date, except for a study that investigated interleukin-1 $\beta$ (IL-1 $\beta$ )-induced upregulation of Snail leading to EMT [44].

We conducted the present study to determine whether selective Cox-2 inhibitors restore the expression of Ecadherin through the downregulation of its transcriptional repressors to suppress the EMT in HNSCC cells, and to determine whether the gene expression levels of the molecules that are implicated in the EMT are correlated with clinicopathological parameters in HNSCC.

\section{Methods}

\section{Cell culture}

We used six cell lines established from human HNSCC: HSC-2 derived from the floor of the mouth; HSC-3, HSC4 , and SAS from the tongue; and $\mathrm{KB}$ and $\mathrm{FaDu}$ from the pharynx. The human fibrosarcoma cell line HT-1080 was used as the negative control for E-cadherin expression. The cells were maintained in Dulbecco's modified Eagle's medium (DMEM) (HSC-2, HSC-3, HSC-4, KB, and $\mathrm{FaDu}$ ), or a mixture of DMEM and Ham's F-12 (SAS), or minimal essential medium (HT-1080), supplemented with $10 \%$ fetal bovine serum (FBS) in a humidified incubator $\left(37^{\circ} \mathrm{C}, 5 \% \mathrm{CO}_{2}\right)$. 


\section{Inhibition of Cox2 using its specific inhibitors}

HSC-2 and HSC-4 cells were seeded in six-well plates at a density of $2 \times 10^{5}$ cells per well and incubated overnight in 10\% FBS medium. The cells were then treated with different selective Cox-2 inhibitors: $50 \mu \mathrm{M}$ of celecoxib (Toronto Research Chemicals, Toronto, Ontario, Canada), $80 \mu \mathrm{M}$ of NS-398 (Cayman Chemical, Ann Arbor, MI, USA), or $20 \mu \mathrm{M}$ of SC-791 (Calbiochem, Darmstadt, Germany). These concentrations of each Cox-2 inhibitor were found to be optimal with no toxic effect on cell viability up to $48 \mathrm{~h}$ based on our preliminary experiments for this purpose. Treatments with only dimethyl sulfoxide (DMSO) (Nacalai Tesque, Kyoto, Japan) used as a solvent for the inhibitors were set as the control. For the evaluation of changes in gene expression associated with Cox-2 inhibition, total RNA was extracted after a $12-\mathrm{h}$ incubation.

\section{Quantitative real-time PCR}

Total RNA from cell lines or fresh frozen tissues was isolated using Trizol reagent (Invitrogen, Carlsbad, CA) and reverse-transcribed into cDNA using random hexamer primer and SuperScript II reverse transcriptase (Invitrogen) according to the manufacturer's instructions. Quantitative real-time polymerase chain reaction (PCR) was performed using the 7500 Fast Real-Time PCR system instrument and software (Applied Biosystems, Foster City, CA) following the manufacturer's protocol. Specific primers and probes were obtained from Applied Biosystems as TaqMan ${ }^{\circ}$ Gene Expression Assays, with the following IDs: human E-cadherin/ $\mathrm{CDH}$ 1, Hs00170423_m1; Snail/SNAI1, Hs00195591_m1; SIP1/ ZFHX1B, Hs00207691_m1; twist/TWIST1, Hs00361186_ m1; Cox-2/PTGS2, Hs01573471_m1; and GAPDH (glyceraldehyde-3-phosphate dehydrogenase)/GAPDH, Hs9999 9905_m1. The PCR amplification conditions were: $20 \mathrm{~s}$ at $95^{\circ} \mathrm{C}$ followed by 40 cycles of $3 \mathrm{~s}$ denaturation at $95^{\circ} \mathrm{C}$ and $30 \mathrm{~s}$ annealing at $60^{\circ} \mathrm{C}$. We quantified the relative expression levels of the genes by the standard curve method, and we compared the levels after normalization using those of GAPDH used as an endogenous control.

\section{Flowcytometric analysis}

For the quantitative analysis of E-cadherin expression at protein level, we harvested cells that had been treated with each of the selective Cox-2 inhibitors for $24 \mathrm{~h}$, using a cell dissociation solution (C 5914, Sigma-Aldrich, St. Louis, MO). Based on our preliminary experiments for this purpose, we identified the following optimal concentrations of each Cox-2 inhibitor: $25 \mu \mathrm{M}$ of celecoxib, $40 \mu \mathrm{M}$ of NS-398, and $10 \mu \mathrm{M}$ of SC-791. After blocking incubation in $0.5 \%$ bovine serum albumin (BSA) in $1 \times$ phosphate-buffered saline (PBS) for $10 \mathrm{~min}$, we labeled the cells with PE-conjugated anti-human E-Cadherin antibody (BioLegend, San Diego, CA) for $1 \mathrm{~h}$, followed by DNA staining using 7-AAD Viability Dye (Beckman Coulter, Indianapolis, IN) for $5 \mathrm{~min}$. Control cells were labeled with PE-conjugated mouse IgG1, $\mathrm{k}$ isotype ctrl (BioLegend). We then analyzed the E-cadherin expression on the cells using the Epics XL-MCL ${ }^{\mathrm{m}}$ Flow Cytometer (Beckman Coulter). Data are presented as the median, mean, and mode of fluorescence intensity of the cells counted.

\section{Western blotting}

The cells treated under the same conditions as those for flowcytometry were lysed in lysis buffer $(50 \mathrm{mM}$ Tris $\mathrm{pH}$ 7.5, 5 mM EDTA, $150 \mathrm{mM} \mathrm{NaCl}, 1 \%$ Triton-X100) containing $1 \mathrm{mM}$ PMSF, $10 \mu \mathrm{g} / \mathrm{ml}$ leupeptin, $1 \mu \mathrm{g} / \mathrm{ml}$ pepstatin, $1 \mathrm{mU} / \mathrm{ml}$ aprotinin, $50 \mathrm{mM}$ sodium fluoride, 2 $\mathrm{mM}$ sodium orthovanadate, and $50 \mathrm{nM}$ Calculin A (Cell signaling). The protein concentration in the cell lysates was determined by the Bradford protein assay (Bio-Rad). Twenty $\mu \mathrm{g}$ of total proteins were separated by SDS-PAGE and transferred to polyvinylidene difluoride membranes (Amersham). The membranes were blocked with 5\% skim milk in PBS containing 0.1\% Tween 20, and probed with mouse anti-E-cadherin antibody (BD Biosciences) at 1:1000 dilution overnight at $4^{\circ} \mathrm{C}$. Subsequently, the membranes were incubated with horseradish peroxidaseconjugated anti-mouse IgG sheep antibody (Amersham) for $1 \mathrm{~h}$. The reactive proteins were visualized using ECL-plus (Amersham) according to the manufacturer's instructions. Equal loading of proteins was confirmed by probing the membranes with mouse anti- $\beta$-actin antibody (Sigma).

\section{Immunofluorescent staining}

HSC-2 cells for immunofluorescent staining of E-cadherin were seeded in slide chambers (IWAKI, Tokyo, Japan) and treated with $25 \mu \mathrm{M}$ of celecoxib or DMSO for $24 \mathrm{~h}$. After washing the cells extensively with $\mathrm{PBS}$, we fixed the cells with cold methanol for $10 \mathrm{~min}$ at $-20^{\circ} \mathrm{C}$. After washing with PBS, the cells were incubated with Alexa Fluor 488-conjugated anti-E-cadherin antibody (Santa Cruz Biotechnology, Dallas, TX) at 1:200 dilution in PBS for $1 \mathrm{~h}$. The nuclei were visualized by staining with Hoechst 33258 (Sigma-Aldrich). Stained cells were then mounted with Prolong Gold Antifade Reagent (Invitrogen). The fluorescent images were captured through a fluorescence microscope (Olympus, Tokyo, Japan).

\section{Patients and tissue samples}

Human tissue specimens were obtained from patients with histologically verified tongue squamous cell carcinoma (TSCC) who underwent primary surgery at the Department of Otorhinolaryngology-Head and Neck Surgery, Keio University Hospital (Tokyo, Japan) between 
2003 and 2011. Informed consent from patients and approval from our Institutional Ethics Review Board were obtained for the use of the clinical materials in the present study. Materials from patients who had received chemotherapy or radiotherapy prior to surgery or who previously had double cancer in the head and neck region were excluded from the study.

In addition to formalin fixation for routine histopathological diagnosis, fresh tumor tissues and, when possible, noncancerous mucosal tissues distant from the TSCC lesion were collected immediately after resection, placed separately in an RNA stabilization regent (RNAlater, Qiagen, Valencia, CA), and stored at $-80^{\circ} \mathrm{C}$ until further analysis. For this study, 40 patients were selected on the basis of the availability of frozen tissue from which RNA of sufficient quality could be extracted. The clinicopathological characteristics of the patients were collected from the medical records, and the tumor stages were classified according to the American Joint Committee on Cancer TNM staging system. We evaluated the histopathological characteristics of the tumor specimens (i.e., histological grade [differentiation], vascular invasion, lymphatic invasion, and perineural invasion) by reviewing each slide stained with hematoxylin and eosin.

\section{Statistical analysis}

The data obtained in the in vitro experiments are presented as mean \pm standard deviation (SD). The mRNA expression levels of CDH1, SIP1, Snail, Twist, and Cox2 in the clinical samples are indicated as median values and ranges because of the skewed distribution of the data. Differences in the mRNA expression levels between paired samples (tumor vs. noncancerous) were assessed using the Wilcoxon signed rank-sum test. Correlations between the mRNA expression levels and clinicopathological factors were evaluated using the Mann-Whitney
U-test or the Spearman rank correlation coefficient. Risk factors of lymph node metastasis were examined using Fisher's exact test, the chi-square test, or the MannWhitney U-test for the univariate analysis, and a multiple logistic regression model with the stepwise selection method for the multivariate analysis. P-values less than 0.05 were considered statistically significant. All statistical analyses were performed using SPSS Ver. 16.0.

\section{Results}

Baseline mRNA expression of Cox-2, CDH-1, and its transcriptional repressors in HNSCC Cells

We used quantitative real-time PCR to evaluate the mRNA expression levels of Cox-2, E-cadherin transcripts $(\mathrm{CDH}-1)$ and its transcriptional repressors (SIP1, Snail, and Twist) in HNSCC cell lines. The relative expression levels of each gene were normalized by dividing each value by that of SAS cells as a calibrator for convenience. As shown in Figure 1A, a trend toward an inverse correlation was found between Cox- 2 and $\mathrm{CDH}-1$ by Spearman rank correlation coefficient $\left(\mathrm{r}_{\mathrm{s}}=-0.714, \mathrm{p}=0.055\right)$. HT1080 cells showed no $\mathrm{CDH}-1$ expression as expected as the negative control for E-cadherin. Figure 1B displays the relative expression levels of the transcriptional repressors. Interestingly, the expression level of SIP1 was revealed to be significantly correlated with that of Cox$2\left(\mathrm{r}_{\mathrm{s}}=0.771, \mathrm{p}=0.042\right)$ and inversely correlated with that of CDH-1 $\left(r_{s}=-0.886, p=0.024\right)$, whereas those of Snail and Twist were shown to correlate with neither Cox-2 nor CDH-1.

Based on these baseline mRNA expression levels, we selected the following cells for the in vitro experiments: HSC-2 expressing a relatively high level of Cox-2 and a low level of $\mathrm{CDH}-1$, and $\mathrm{HSC}-4$ expressing a relatively low level of Cox-2 and a high level of CDH-1.
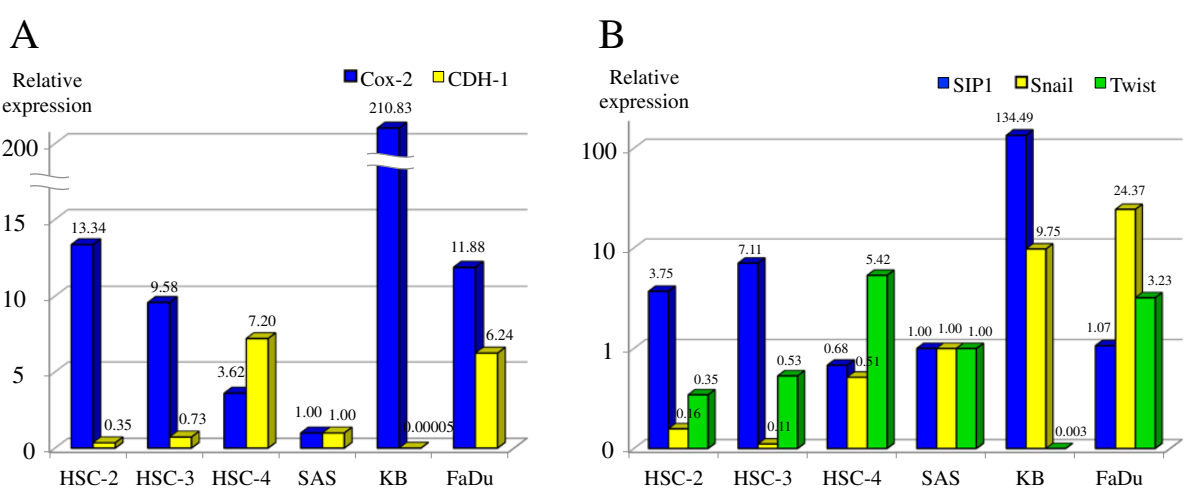

Figure 1 Baseline mRNA expression of Cox-2, $\mathrm{CDH}-1$ and its transcriptional repressors in HNSCC cells. The mRNA expression levels of each gene in the HNSCC cell lines were assessed by quantitative real-time PCR. The relative expression levels were normalized by dividing each value by that of SAS as a calibrator for convenience. A: Cox-2 and CDH-1. B: SIP1, Snail, and Twist. While a trend toward an inverse correlation was found between Cox-2 and CDH-1 $\left(r_{s}=-0.714, p=0.055\right)$, SIP1 was shown to significantly correlate with Cox-2 $\left(r_{s}=0.771, p=0.042\right)$ and to inversely correlate with $\mathrm{CDH}-1\left(\mathrm{r}_{\mathrm{s}}=-0.886, \mathrm{p}=0.024\right)$ by Spearman rank correlation coefficient. 


\section{Alterations in the mRNA expressions of $\mathrm{CDH}-1$ and its transcriptional repressors by Cox-2 inhibition}

We examined the effect of Cox-2 inhibition on the mRNA expressions of CDH-1 and its transcriptional repressors in the cell lines HSC-2 and HSC-4, using the three selective Cox-2 inhibitors celecoxib, NS-398, and SC-791. As regards the dose and exposure time of Cox-2 inhibitor, because we observed neither time-dependent nor dose-dependent manner in the regulation with each Cox-2 inhibitor in our preliminary experiments, the results were shown with the doses and exposure times considered to be optimal for each Cox-2 inhibitor and each purpose. In the HSC-2 cells, Cox-2 inhibition upregulated the $\mathrm{CDH}-1$ expression compared to DMSO treatment as the control, increasing by 1.60-, 1.93-, and 1.20-fold with celecoxib, NS-398, and SC-791, respectively (Figure 2A). In contrast, Cox-2 inhibition in the HSC-4 cells resulted in relatively less upregulation of $\mathrm{CDH}-1$ expression (Figure 2B). These results suggest that the extent of the effect of Cox-2 inhibition may vary depending on the cell type and presumably on the baseline expression levels of both CDH-1 and Cox-2 in each cell.

In line with these results, all three transcriptional repressors of E-cadherin were clearly downregulated in the HSC-2 cells by each of the Cox-2 inhibitors, with decreasing by $0.18-0.34-, 0.15-0.32-$, and $0.35-0.47$-fold in SIP1, Snail, and Twist, respectively (Figure 2C), whereas the Cox-2 inhibition in the HSC-4 cells led to relatively less downregulation of these transcriptional repressors (Figure 2D).

\section{Restoration of membranous E-cadherin expression by Cox-2 inhibition}

The Cox-2 inhibition-induced upregulation of E-cadherin in the HNSCC cells at protein level was confirmed by Western blotting (Figure 3A). In accord with its mRNA expressions, E-cadherin expression in the HSC-2 cells was noticeably enhanced by each of the Cox-2 inhibitors compared to DMSO treatment, whereas relatively less upregulation of E-cadherin expression was shown in the HSC-4 cells.

Because the function of E-cadherin in intercellular adhesion is maintained through the membranous localization of this molecule, we also evaluated the alteration of its protein expression on the cell surface using a flowcytometer. In line with aforementioned results, Cox-2 inhibition elevated the cell surface expression of E-cadherin compared to DMSO treatment in the HSC-2 cells, increasing by more than 1.76-, 1.47-, and 1.21-fold with celecoxib, NS-398, and SC-791, respectively (Figure 3B and D), whereas Cox-2 inhibition in the HSC-4 cells
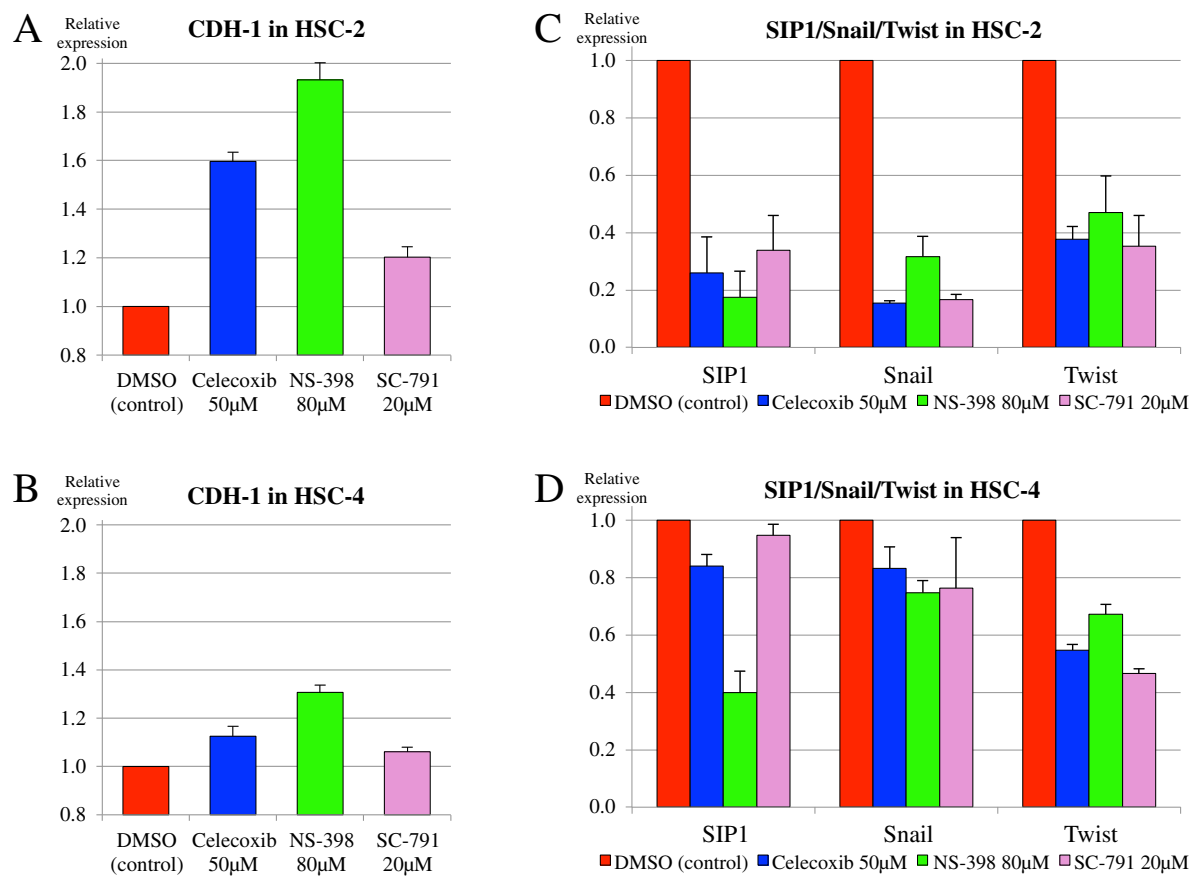

Figure 2 Alterations in the mRNA expression of $\mathrm{CDH}-1$ and its transcriptional repressors by Cox-2 inhibition. The effect of Cox-2 inhibition on the mRNA expressions of $\mathrm{CDH}-1$ and its transcriptional repressors (SIP1, Snail, and Twist) was examined by quantitative real-time PCR using three different selective Cox-2 inhibitors: celecoxib, NS-398, and SC-791. A: In HSC-2 cells, Cox-2 inhibition upregulated the CDH-1 expression compared to DMSO treatment as the control. B: In HSC-4 cells, Cox-2 inhibition resulted in relatively less upregulation of CDH-1 expression. C: In HSC-2 cells, all three transcriptional repressors were clearly downregulated by each of the Cox-2 inhibitors. D: In HSC-4 cells, Cox-2 inhibition led to relatively less downregulation of these transcriptional repressors. 


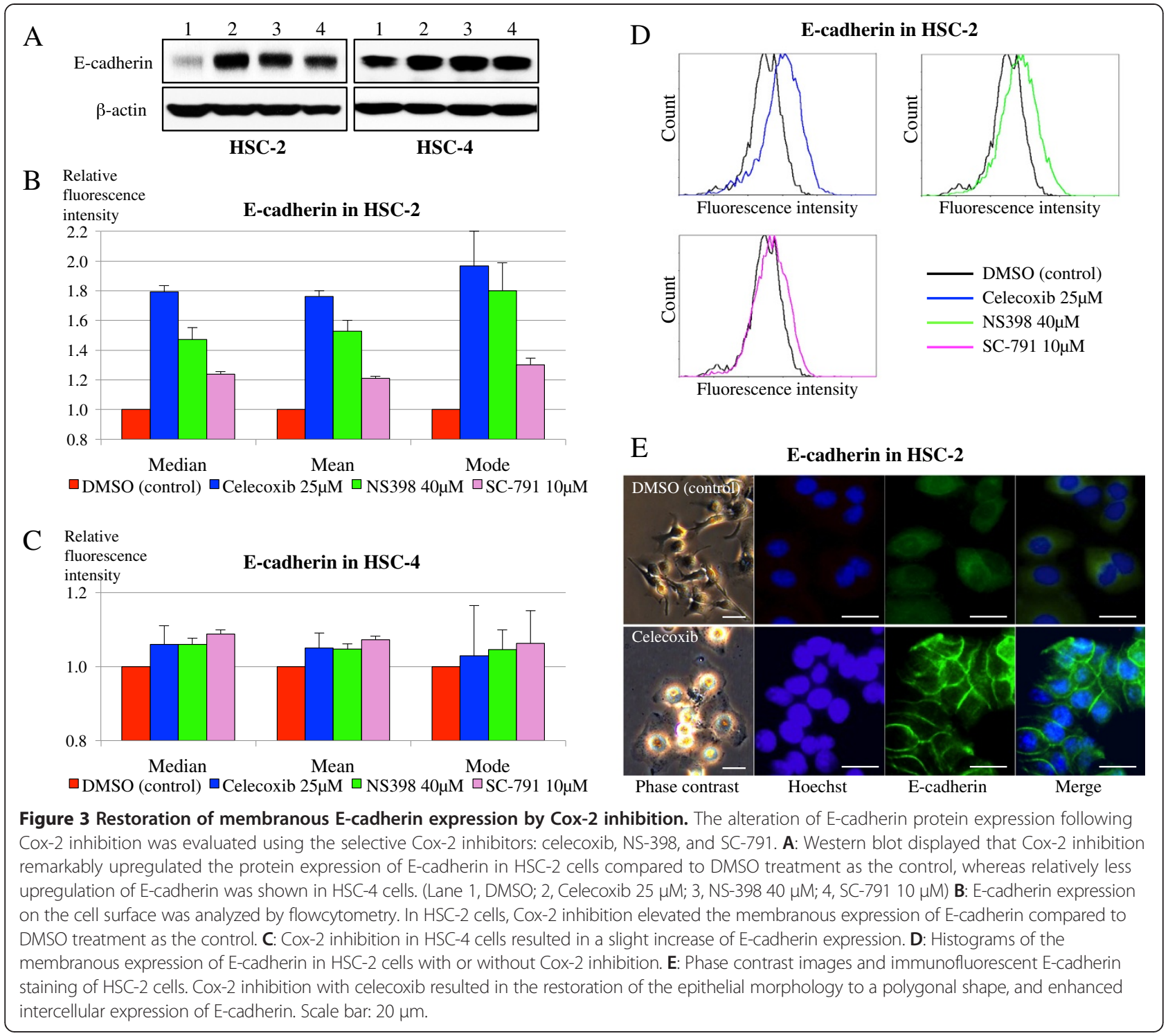

resulted in a slight increase of E-cadherin expression by less than 1.10-fold with any of the inhibitors (Figure 3C).

The cellular morphology and the localization of Ecadherin expression in the HSC-2 cells were further evaluated by a phase contrast microscope and immunofluorescent staining, respectively. As shown in Figure 3E, Cox-2 inhibition with celecoxib resulted in the restoration of the epithelial morphology to a polygonal shape, and enhanced intercellular expression of E-cadherin compared to DMSO treatment.

\section{Comparison of the mRNA expressions of Cox-2 and CDH-1} between TSCC and corresponding noncancerous tissues From among the 40 patients with TSCC whose freshfrozen tumor specimens were available for the present study, corresponding noncancerous mucosal tissues were also collected in 20 patients. In these paired samples, as shown in Table 1, the Wilcoxon signed rank-sum test revealed that the mRNA expression level of Cox-2 was significantly higher in the TSCC tissues than in the adjacent noncancerous mucosal tissues (median values, 5.865 vs. $3.707, \mathrm{p}=0.018$ ). In contrast, the CDH-1 mRNA expression level was significantly lower in the TSCC tissue than in the noncancerous mucosal tissue (median values, 11.249 vs. $17.639, \mathrm{p}=0.024$ ). However, no significant inverse correlation between $\mathrm{Cox}-2$ and $\mathrm{CDH}-1$ expression was observed in these samples, or only in 40 TSCC tissues.

Correlations between the mRNA expression levels of each gene and clinicopathological factors

We evaluated the correlations between the mRNA expression levels of each gene in the TSCC tissues and the clinicopathological factors of the 40 patients with TSCC, 
Table 1 Comparison of gene expression levels between TSCC and corresponding noncancerous tissues

\begin{tabular}{lcccc}
\hline & & $\begin{array}{c}\text { TSCC tissue } \\
(\mathbf{n}=\mathbf{2 0})\end{array}$ & $\begin{array}{c}\text { Noncancerous } \\
\text { tissue }(\mathbf{n}=\mathbf{2 0})\end{array}$ & p value $^{\mathbf{a}}$ \\
\hline Cox-2 & median & 5.865 & 3.707 & $0.018^{*}$ \\
& (range) & $(0.427-52.766)$ & $(0.394-24.626)$ & \\
$\mathrm{CDH}-1$ & median & 11.249 & 17.639 & $0.024^{*}$ \\
& (range) & $(0.048-24.494)$ & $(2.321-36.348)$ & \\
\hline
\end{tabular}

${ }^{a}$ Wilcoxon signed rank sum test.

*Statistically significant.

TSCC = tongue squamous cell carcinoma.

as shown in Table 2. Higher Cox-2 mRNA expression was significantly correlated with lymph node metastasis $(p=0.037)$, while lower $\mathrm{CDH}-1$ expression was correlated with both advanced T-classification $(\mathrm{p}=0.041)$ and lymph node metastasis $(\mathrm{p}=0.020)$. Although the mRNA expressions of SIP1, Snail, and Twist were associated with neither lymph node metastasis nor T-classification, higher expression of each of these three genes was significantly correlated with the histological grade $(\mathrm{p}=$ 0.004, 0.021, and 0.019, respectively). Higher expressions of SIP1 and Twist were also correlated with perineural invasion ( $\mathrm{p}=0.016$ and 0.008 , respectively). None of the genes examined were associated with other clinicopathological factors, including age, gender, vascular invasion, and lymphatic invasion.

\section{Univariate and multivariate analyses of risk factors affecting lymph node metastasis}

To determine the risk factors predictive of lymph node metastasis, we further examined the correlation of lymph node metastasis with other clinicopathological factors. As shown in Table 3, advanced T-classification was significantly correlated with lymph node metastasis $(p=0.036)$. All other clinicopathological factors showed no significant correlation with lymph node metastasis, although lymphatic invasion tended to be associated with lymph node metastasis $(\mathrm{p}=0.069)$.

We used a multiple logistic regression model to further analyze the variables that were significantly correlated with lymph node metastasis in the aforementioned univariate analyses. As shown in Table 4, lower CDH-1 mRNA expression alone, and not Cox-2 mRNA expression or T-classification, was found to be the independent risk factor affecting lymph node metastasis in this series (odds ratio $=0.905, \mathrm{p}=0.041$ ).

\section{Discussion}

Our in vitro results revealed that, in HNSCC cells, the selective Cox-2 inhibitors led to the suppression of the EMT by restoring the expression of E-cadherin through the downregulation of its transcriptional repressors. Moreover, the extent of the effect of Cox-2 inhibition was shown to depend on the baseline expression levels of both E-cadherin and Cox-2 in each cell; i.e., tumor cells expressing lower E-cadherin and higher Cox-2 are expected to be more sensitive to Cox-2 inhibition in terms of the restoration of E-cadherin expression. Such a finding is consistent with a previous study of bladder cancer cells using another Cox-2 inhibitor, etodolac. In that study, etodolac upregulated E-cadherin expression only in T24 cells, which express the highest level of Cox-2 and the lowest level of E-cadherin; it did not do so in 5637 cells or K47 cells, which express a lower level of Cox-2 and a higher level of E-cadherin [42]. Interestingly, using the same three bladder cancer cell lines and three different Cox-2 inhibitors (etodolac, celecoxib, and NS-398), Adhim et al. found that E-cadherin mRNA was enhanced in all three cell lines by at least two Cox-2 inhibitors in each cell line, although the fold of increase remained the highest in T24 cells [43]. These and our results suggests that the suitability of Cox-2 inhibitor application could be assessed by predicting its anti-cancer effects in advance based on the baseline expression level of Cox-2 and certain of its downstream effector molecules.

Aside from the use of Cox-2 inhibitors, the Cox-2dependent regulation of E-cadherin expression in HNSCC cells was demonstrated in a study using KB cells transfected with Cox-2 cDNA and gene silencing with Cox-2 siRNA, although the specific signaling pathway between Cox-2 and E-cadherin was not referred to [45]. In HNSCC cells, St. John et al. elucidated that proinflammatory cytokine IL-1 $\beta$ induces downregulation of E-cadherin through the Cox-2/Snail pathway, which is blocked by the selective Cox-2 inhibition using celecoxib or Cox-2 small hairpin RNA [44]. Those findings also corroborate our results regarding the Cox-2 inhibition-induced restoration of E-cadherin expression in HNSCC.

Regarding the direct mechanisms underlying the downregulation of E-cadherin, it has been suggested that transcriptional repression and promoter hypermethylation are primarily responsible in sporadic carcinoma, whereas other mechanisms such as genomic deletion and loss of heterozygosity associated with germline mutation are observed in hereditary carcinoma [6-8]. According to the study that examined $\mathrm{CpG}$ island methylation around the promoter region of CDH-1 in HNSCC cell lines by methylation-specific PCR, the methylation was partially found in the HSC-2 cells, but not in the HSC-4 cells [46], which may also accounts for the low base-line expression of E-cadherin in the HSC-2 cells.

In our present in vitro study, the mRNA expression level of SIP1, but not those of Snail or Twist, showed a significant inverse correlation with that of $\mathrm{CDH}-1$, which is in agreement with previous findings in HNSCC, breast, and hepatocellular carcinoma cells [9,47-49]. We observed that the SIP1 expression was also significantly 
Table 2 Correlation between gene expression levels and clinicopathological factors

\begin{tabular}{|c|c|c|c|c|c|c|c|c|c|c|c|c|c|}
\hline Variable & & $n$ & & Cox-2 & $p$ value & SIP1 & $p$ value & Snail & $p$ value & Twist & $p$ value & $\mathrm{CDH}-1$ & $p$ value \\
\hline \multirow[t]{4}{*}{$\overline{\text { Age }^{a}}$} & $<60$ & 25 & median & 3.964 & 0.583 & 3.191 & 0.773 & 1.071 & 0.273 & 12.469 & 0.119 & 13.681 & 0.878 \\
\hline & & & (range) & $(0.640-61.171)$ & & $(0.035-17.376)$ & & $(0.020-6.229)$ & & $(0.000-64.312)$ & & $(0.100-45.381)$ & \\
\hline & $\geqq 60$ & 15 & median & 4.443 & & 2.926 & & 0.936 & & 6.947 & & 13.881 & \\
\hline & & & (range) & $(0.427-52.766)$ & & $(0.059-9.482)$ & & $(0.099-2.361)$ & & $(0.936-20.548)$ & & $(0.841-24.494)$ & \\
\hline \multirow[t]{4}{*}{ Gender $^{a}$} & Male & 35 & median & 4.037 & 0.817 & 3.200 & 0.247 & 0.986 & 0.611 & 9.794 & 0.746 & 12.670 & 0.379 \\
\hline & & & (range) & $(0.427-61.171)$ & & $(0.035-17.376)$ & & $(0.020-6.229)$ & & $(0.000-64.312)$ & & $(0.100-45.381)$ & \\
\hline & Female & 5 & median & 4.331 & & 1.454 & & 1.191 & & 9.102 & & 19.520 & \\
\hline & & & (range) & $(3.223-6.581)$ & & $(0.677-7.218)$ & & $(0.562-2.361)$ & & $(5.989-12.900)$ & & $(5.367-23.448)$ & \\
\hline \multirow[t]{4}{*}{ T classification ${ }^{b}$} & 1 & 2 & coefficient & $\mathrm{rs}=-0.264$ & 0.114 & $\mathrm{rs}=0.089$ & 0.583 & $\mathrm{rs}=-0.017$ & 0.919 & $\mathrm{rs}=0.223$ & 0.170 & $r s=-0.327$ & $0.041^{*}$ \\
\hline & 2 & 10 & & & & & & & & & & & \\
\hline & 3 & 22 & & & & & & & & & & & \\
\hline & 4 & 6 & & & & & & & & & & & \\
\hline \multirow[t]{4}{*}{ LN metastasis ${ }^{a}$} & $N(-)$ & 15 & median & 2.399 & $0.037^{*}$ & 2.926 & 0.964 & 0.983 & 0.800 & 6.947 & 0.226 & 18.801 & $0.020^{*}$ \\
\hline & & & (range) & $(0.427-6.092)$ & & $(0.059-11.250)$ & & $(0.193-5.137)$ & & $(0.000-42.360)$ & & $(0.841-45.381)$ & \\
\hline & $N(+)$ & 25 & median & 4.443 & & 3.602 & & 1.094 & & 12.037 & & 10.688 & \\
\hline & & & (range) & $(1.379-61.171)$ & & $(0.035-17.376)$ & & $(0.020-6.229)$ & & $(0.936-64.312)$ & & $(0.100-23.697)$ & \\
\hline \multirow[t]{3}{*}{ Histological grade ${ }^{b}$} & । & 21 & coefficient & $r s=0.155$ & 0.338 & $r s=0.462$ & $0.004^{*}$ & $r s=0.374$ & $0.021^{*}$ & $r s=0.381$ & $0.019^{*}$ & $r s=-0.026$ & 0.873 \\
\hline & $\|$ & 12 & & & & & & & & & & & \\
\hline & III & 7 & & & & & & & & & & & \\
\hline \multirow[t]{4}{*}{ Vascular invasion ${ }^{a}$} & Negative & 32 & median & 3.478 & 0.133 & 3.393 & 0.360 & 1.006 & 0.608 & 9.369 & 0.913 & 14.999 & 0.085 \\
\hline & & & (range) & $(0.640-61.171)$ & & $(0.035-17.376)$ & & $(0.020-5.538)$ & & $(0.000-64.312)$ & & $(0.100-45.381)$ & \\
\hline & Positive & 8 & median & 10.759 & & 2.250 & & 1.264 & & 9.794 & & 7.799 & \\
\hline & & & (range) & $(0.427-43.355)$ & & $(0.059-6.356)$ & & $(0.193-6.229)$ & & $(1.246-29.053)$ & & $(0.841-23.697)$ & \\
\hline \multirow[t]{4}{*}{ Lymphatic invasion ${ }^{\text {a }}$} & Negative & 22 & median & 4.037 & 0.800 & 3.939 & 0.195 & 0.936 & 0.554 & 9.027 & 0.554 & 15.966 & 0.192 \\
\hline & & & (range) & $(0.640-61.171)$ & & $(0.035-11.250)$ & & $(0020-5.137)$ & & $(0.000-64.312)$ & & $(1.373-38.234)$ & \\
\hline & Positive & 18 & median & 4.733 & & 2.155 & & 1.104 & & 10.915 & & 10.694 & \\
\hline & & & (range) & $(0.427-60.921)$ & & $(0.059-17.376)$ & & $(0.086-6.229)$ & & $(0.936-31.933)$ & & $(0.100-45.381)$ & \\
\hline \multirow[t]{4}{*}{ Perineural invasion ${ }^{a}$} & Negative & 30 & median & 4.128 & 0.841 & 2.212 & $0.016^{*}$ & 1.006 & 0.286 & 7.720 & $0.008^{*}$ & 14.891 & 0.617 \\
\hline & & & (range) & $(0.427-61.171)$ & & $(0.035-11.250)$ & & $(0.020-5.137)$ & & $(0.000064 .312)$ & & $(0.100-38.234)$ & \\
\hline & Positive & 10 & median & 5.247 & & 6.345 & & 1.114 & & 13.886 & & 11.907 & \\
\hline & & & (range) & $(0.640-60.921)$ & & $(2.250-17.376)$ & & $(0.458-6.229)$ & & $(9.027-31.933)$ & & $(2.089-45.381)$ & \\
\hline
\end{tabular}

${ }^{\mathrm{a}}$ Mann-Whithey $\mathrm{U}$ test, ${ }^{\mathrm{b}}$ Spearman rank correlation coefficient.

*Statistically significant.

$\mathrm{LN}=$ lymph node, $r s=$ correlation coefficient. 
Table 3 Univariate analysis of clinicopathological factors predictive of lymph node metastasis

\begin{tabular}{|c|c|c|c|c|c|c|c|}
\hline \multirow{2}{*}{$\frac{\text { Variable }}{\mathrm{Age}^{\mathrm{a}}}$} & \multirow[b]{2}{*}{$<60$} & \multirow{2}{*}{$\frac{\mathbf{n}}{25}$} & \multicolumn{2}{|c|}{ LN metastasis $(-) n=15$} & \multicolumn{2}{|c|}{ LN metastasis $(+) n=25$} & \multirow{2}{*}{$\begin{array}{r}\text { p value } \\
0.724\end{array}$} \\
\hline & & & 9 & $(36.0 \%)$ & 16 & $(64.0 \%)$ & \\
\hline & $\geqq 60$ & 15 & 6 & $(40.0 \%)$ & 9 & $(60.0 \%)$ & \\
\hline \multirow[t]{2}{*}{ Gender $^{a}$} & Male & 35 & 15 & $(42.9 \%)$ & 20 & $(57.1 \%)$ & 0.081 \\
\hline & Female & 5 & 0 & $(0.0 \%)$ & 5 & $(100.0 \%)$ & \\
\hline \multirow[t]{4}{*}{ T classification ${ }^{\mathrm{b}}$} & 1 & 2 & 1 & $(50.0 \%)$ & 1 & $(50.0 \%)$ & $0.036^{*}$ \\
\hline & 2 & 10 & 7 & $(70.0 \%)$ & 3 & $(30.0 \%)$ & \\
\hline & 3 & 22 & 4 & $(18.2 \%)$ & 18 & $(81.8 \%)$ & \\
\hline & 4 & 6 & 3 & $(50.0 \%)$ & 3 & $(50.0 \%)$ & \\
\hline \multirow[t]{3}{*}{ Histological grade ${ }^{b}$} & । & 21 & 7 & (33.3\%) & 14 & $(66.7 \%)$ & 0.551 \\
\hline & $\|$ & 12 & 6 & $(50.0 \%)$ & 6 & $(50.0 \%)$ & \\
\hline & ॥I & 7 & 2 & $(28.6 \%)$ & 5 & $(71.4 \%)$ & \\
\hline \multirow[t]{2}{*}{ Vascular invasion ${ }^{a}$} & Negative & 32 & 13 & $(40.6 \%)$ & 19 & $(59.4 \%)$ & 0.350 \\
\hline & Positive & 8 & 2 & (25.0\%) & 6 & $(75.0 \%)$ & \\
\hline \multirow[t]{2}{*}{ Lymphatic invasion $^{a}$} & Negative & 22 & 11 & (50.0\%) & 11 & (50.0\%) & 0.069 \\
\hline & Positive & 18 & 4 & $(22.2 \%)$ & 14 & (77.8\%) & \\
\hline \multirow[t]{2}{*}{ Perineural invasion ${ }^{a}$} & Negative & 30 & 13 & (43.3\%) & 17 & $(56.7 \%)$ & 0.174 \\
\hline & Positive & 10 & 2 & (20.0\%) & 8 & (80.0\%) & \\
\hline
\end{tabular}

${ }^{\mathrm{a}}$ Fisher's exact test, ${ }^{\mathrm{b}} \mathrm{Chi}$-square test.

*Statistically significant.

$\mathrm{LN}=$ lymph node.

correlated with Cox-2, suggesting the possibility that SIP1 acts as a principal effector in the Cox-2-dependent regulation of E-cadherin expression in HNSCC. However, the Cox-2 inhibitors used in the present study led to the downregulation of not only SIP1 but also Snail and Twist comparably, indicating the similar importance of each transcriptional repressor in this pathway. In NSCLC cells, ZEB1 and Snail were found to be repressors responsible for the regulation of E-cadherin downstream of Cox-2/PGE 2 [37], whereas in bladder cancer cells Cox-2 inhibitors downregulated all of the Ecadherin repressors examined: Snail, Slug, Twist, and ZEB1 [43]. Aside from the implication of Cox-2, in breast cancer cells, receptor activator of NF- $\mathrm{kB}$ ligand (RANKL) was revealed to downregulate the E-cadherin expression by activating the NF- $\mathrm{kB}$ pathway and enhancing Snail and Twist expression [50]. In HNSCC cells, inhibition of Akt activity was shown to decrease NF- $\mathrm{kB}$ signaling, thereby downregulate the expression of Snail and Twist, but not SIP-1, to induce the mesenchymal-

Table 4 Multivariate analysis of factors predictive of lymph node metastasis

\begin{tabular}{lccc}
\hline Variable & Odds ratio & 95\% confidence interval & p value $^{\mathbf{a}}$ \\
\hline T-classification & 1.119 & $0.418-2.993$ & 0.823 \\
Cox-2 & 1.011 & $0.965-1.060$ & 0.648 \\
$\mathrm{CDH}-1$ & 0.905 & $0.822-0.996$ & $0.041^{*}$ \\
\hline
\end{tabular}

${ }^{a}$ Multiple logistic regression model.

*Statistically significant. to-epithelial reverting transition [51]. Although we did not evaluate the expressions of ZEB1 and Slug, our results verified these reports in terms of the direct role of transcriptional repressors in the Cox-2-dependent regulation of E-cadherin.

In addition to the suppression of the EMT, some other anti-cancer effects of Cox-2 inhibitors in HNSCC have been reported, which include the inhibition of VEGF-A expression by celecoxib [15], the suppression of invasiveness by NS-398 [52,53] and celecoxib [54], the inhibition of proliferation by celecoxib, NS-398, nimesulide, and meloxicam [54,55], and the induction of apoptosis by celecoxib [55]. Since a close relationship is likely between the EMT and enhanced cell migration, the Cox-2 inhibitor-induced suppression of the EMT may also contribute to the attenuation of the invasiveness of cancer cells. Considering the multifaceted function of Cox-2 itself, a variety of mechanisms are thought to be involved in the anti-cancer effects of selective Cox-2 inhibitors, and these mechanisms are presumed to exert their effects cooperatively.

In the clinical samples that we examined, compared to adjacent noncancerous mucosal tissue, the mRNA expression level of $\mathrm{CDH}-1$ was significantly lower in the TSCC tissue as expected, although functional E-cadherin is supposed to be assessed by its membranous expression. In addition, we found that the mRNA expression level of Cox-2 was significantly higher in the TSCC tissue, which is consistent with the previous studies 
including those that examined HNSCC $[14,15]$. As for a possible inverse correlation between Cox-2 and Ecadherin expressions, we found a trend toward an inverse correlation in the HNSCC cell lines examined, whereas no correlation was observed in the clinical samples of TSCC. Inconsistent statistical results have been reported even in immunohistochemical evaluations of cancers other than HNSCC: although a significant inverse correlation between Cox-2 and E-cadherin expressions was seen in bladder cancer [41], no correlation between them was revealed in gastric cancer [40], the latter of which is in agreement with our result assessed by quantitative real-time PCR. Such discrepancies could be attributed not only to differences in the sites of cancer origin and sample size, but also to differences in the studies' evaluation methods and statistical methods. Aside from these statistical analyses, an inverse expression pattern between Cox-2 and E-cadherin in each of individual cases was seen by immunohistochemical observation in NSCLC and colon cancer $[37,56]$. Considering tissue heterogeneity in terms of the localized expression of particular molecules along with the abovementioned immunohistochemical observation, we speculate that the extent of the upregulation of Cox-2 and its possible downregulation of E-cadherin may depend on microscopically specific sites such as the invasive front or the inside of cancer nests, which would not necessarily be reflected in any statistical analysis or in homogenized samples at all.

Regarding the correlations with clinical parameters in TSCC, while univariate analysis demonstrated that the mRNA expressions of both higher Cox-2 and lower $\mathrm{CDH}-1$ were significantly correlated with lymph node metastasis, the multivariate analysis revealed that a lower CDH-1 mRNA expression level was the only independent predictor of lymph node metastasis in this cohort. These results suggest that the induction of the EMT, regardless of dependency on its various upstream pathways, is closely implicated in the development of lymphogeneous metastasis. However, the predictive reliability of a lower CDH-1 mRNA expression level should be further validated using much larger independent cohorts. The result regarding Cox-2, even though it was confined to the univariate analysis, is in accord with the preceding immunohistochemical studies of HNSCC, although those were also missing multivariate analysis $[15,16]$. Considering its role in the regulation of Ecadherin expression, Cox-2 is thought to indirectly contribute to lymph node metastasis, at least in part through the induction of the EMT. On the other hand, our result regarding $\mathrm{CDH}-1$ is consistent with the previous immunohistochemical studies of oral SCC that reported a significant correlation between reduced Ecadherin expression and lymph node metastasis [57-60], but not with others that showed no correlation between them [61-63], although all of those studies lacked multivariate analysis. These contradictory results seemed to be attributable to the quite variable criteria used to evaluate the extent of immunostaining intensity, which inevitably seems prone to subjective judgment. In addition, since each tumor specimen consists of heterogeneous cancer cell populations that show different behaviors, staining scores could vary depending on the tumor portion selected for examination. To overcome such uncertainties accompanying immunohistochemical evaluation, instead we quantified mRNA expression levels in homogenates from whole frozen blocks of tumor samples. However, those data must still be interpreted cautiously because the differences in expression levels according to microscopically distinct sites and cellular localization cannot be considered, and it is thus possible that certain correlations would be missed.

Practically, if clinical NO (cN0) patients with occult lymph node metastasis can be discriminated accurately from other cNO patients, we could apply neck dissection exclusively for those selected patients in advance of the inevitable development of delayed neck metastasis. Therefore, from a clinical point of view, the prediction of lymph node metastasis is genuinely meaningful in cNO cases. Among the reliable studies conducted to identify predictive markers of delayed or occult neck metastasis within clinical stage I/II (cT1-2 N0) oral squamous cell carcinoma by a multivariate analysis, tumor thickness or depth has been most accepted as an independent histopathological parameter [64]. However, the downregulation of E-cadherin was recently revealed by us and others to be one of the independent molecular predictors of delayed neck metastasis even in such a limited patient population $[9,65,66]$. These previous and present results suggest that the restoration of E-cadherin expression by inhibiting any of the upstream signals promoting the EMT may prevent the initiation and progression of lymph node metastasis of HNSCC. Further investigations are indispensable to establish the optimal standard to evaluate the risk of metastasis using molecular markers related to the EMT.

In conclusion, our findings suggest that the downregulation of $\mathrm{CDH}-1$ resulting from the induction of the EMT is closely involved in lymph node metastasis in HNSCC. The expression profiles of EMT-related molecular makers in primary tumors are thought to be informative to predict the clinicopathological behavior of HNSCC. In addition, the appropriately selective administration of selective Cox-2 inhibitors may lead to an anti-metastatic effect as suppression of the EMT by restoring E-cadherin expression through the downregulation of its transcriptional repressors, cooperatively with various other mechanisms. 


\section{Competing interests}

There are no financial or other relationships that may lead to a conflict of interests.

\section{Authors' contributions}

RF and YI (contributed equally) conceived of and designed the study, conducted the experiments, performed the data analysis, and drafted the manuscript. KS and NS carried out the experiments. KS, SS, NH, and KOt participated in the design of the study and conducted the experiments. YS and YW supported the experiments and the data analysis. KK provided and reviewed the histopathological diagnosis of clinical specimens. $\mathrm{HO}, \mathrm{T}$, and MF participated in the design of the study and the data analysis. KOg provided general support to conception of the study. All authors read and approved the final manuscript.

\section{Acknowledgement}

This study was supported in part by Grants-in-Aid for Scientific Research (C) from MEXT (Number 222591917), and by Keio Gijuku Academic Development Funds to Y. Imanishi. We thank the Core Instrumentation Facility, Keio University School of Medicine for technical assistance.

\section{Author details}

'Department of Otorhinolaryngology-Head and Neck Surgery, Keio University School of Medicine, 35 Shinanomachi, Shinjuku, Tokyo 160-8582, Japan. ${ }^{2}$ Department of Functional Genomics, Faculty of Pharmaceutical Sciences, Himeji Dokkyo University, Himeji, Japan. ${ }^{3}$ Department of Otorhinolaryngology, Saiseikai Utsunomiya Hospital, Utsunomiya, Japan. ${ }^{4}$ Department of Otorhinolaryngology, Kawasaki Municipal Hospital, Kawasaki, Japan. ${ }^{5}$ Department of Otorhinolaryngology-Head and Neck Surgery, Keiyu Hospital, Yokohama, Japan. ${ }^{6}$ Department of Pathology, Keio University School of Medicine, Tokyo, Japan. ${ }^{7}$ National Institute of Sensory Organs, National Tokyo Medical Center, Tokyo, Japan.

Received: 21 March 2014 Accepted: 3 May 2014

Published: 10 May 2014

\section{References}

1. Haddad RI, Shin DM: Recent advances in head and neck cancer. N Engl J Med 2008, 359:1143-1154.

2. Hunter KD, Parkinson EK, Harrison PR: Profiling early head and neck cancer. Nat Rev Cancer 2005, 5:127-135.

3. DiTroia JF: Nodal metastases and prognosis in carcinoma of the oral cavity. Otolaryngol Clin North Am 1972, 5:333-342.

4. Cerezo L, Millan I, Torre A, Aragon G, Otero J: Prognostic factors for survival and tumor control in cervical lymph node metastases from head and neck cancer. A multivariate study of 492 cases. Cancer 1992, 69:1224-1234

5. Leemans CR, Tiwari R, Nauta JJ, van der Waal I, Snow GB: Recurrence at the primary site in head and neck cancer and the significance of neck lymph node metastases as a prognostic factor. Cancer 1994, 73:187-190.

6. Berx G, Raspe E, Christofori G, Thiery JP, Sleeman JP: Pre-EMTing metastasis? Recapitulation of morphogenetic processes in cancer. Clin Exp Metastasis 2007, 24:587-597.

7. Kalluri $R$, Weinberg RA: The basics of epithelial-mesenchymal transition. J Clin Invest 2009, 119:1420-1428.

8. Baranwal S, Alahari SK: Molecular mechanisms controlling E-cadherin expression in breast cancer. Biochem Biophys Res Commun 2009, 384:6-11.

9. Sakamoto K, Imanishi Y, Tomita T, Shimoda M, Kameyama K, Shibata K, Sakai N, Ozawa H, Shigetomi S, Fujii R, Fujii M, Ogawa K: Overexpression of SIP1 and downregulation of E-cadherin predict delayed neck metastasis in stage $1 / /$ oral tongue squamous cell carcinoma after partial glossectomy. Ann Surg Oncol 2012, 19:612-619.

10. Dubois RN, Abramson SB, Crofford L, Gupta RA, Simon LS, Van De Putte LB, Lipsky PE: Cyclooxygenase in biology and disease. FASEB J 1998, 12:1063-1073.

11. Tsujii M, Kawano S, Tsuji S, Sawaoka H, Hori M, DuBois RN: Cyclooxygenase regulates angiogenesis induced by colon cancer cells. Cell 1998, 93:705-716.

12. Dannenberg AJ, Altorki NK, Boyle JO, Dang C, Howe LR, Weksler BB, Subbaramaiah K: Cyclo-oxygenase 2: a pharmacological target for the prevention of cancer. Lancet Oncol 2001, 2:544-551.

13. Dannenberg AJ, Subbaramaiah K: Targeting cyclooxygenase-2 in human neoplasia: rationale and promise. Cancer Cell 2003, 4:431-436.
14. Chan G, Boyle JO, Yang EK, Zhang F, Sacks PG, Shah JP, Edelstein D, Soslow RA, Koki AT, Woerner BM, Masferrer JL, Dannenberg AJ: Cyclooxygenase-2 expression is up-regulated in squamous cell carcinoma of the head and neck. Cancer Res 1999, 59:991-994.

15. Gallo O, Franchi A, Magnelli L, Sardi I, Vannacci A, Boddi V, Chiarugi V, Masini E: Cyclooxygenase-2 pathway correlates with VEGF expression in head and neck cancer. Implications for tumor angiogenesis and metastasis. Neoplasia 2001, 3:53-61.

16. Kyzas PA, Stefanou D, Agnantis NJ: COX-2 expression correlates with VEGF-C and lymph node metastases in patients with head and neck squamous cell carcinoma. Mod Pathol 2005, 18:153-160.

17. Wiese FW, Thompson PA, Kadlubar FF: Carcinogen substrate specificity of human COX-1 and COX-2. Carcinogenesis 2001, 22:5-10.

18. Tsujii M, DuBois RN: Alterations in cellular adhesion and apoptosis in epithelial cells overexpressing prostaglandin endoperoxide synthase 2 . Cell 1995, 83:493-501.

19. Sun $Y$, Tang XM, Half E, Kuo MT, Sinicrope FA: Cyclooxygenase-2 overexpression reduces apoptotic susceptibility by inhibiting the cytochrome c-dependent apoptotic pathway in human colon cancer cells. Cancer Res 2002, 62:6323-6328.

20. Stolina M, Sharma S, Lin Y, Dohadwala M, Gardner B, Luo J, Zhu L, Kronenberg M, Miller PW, Portanova J, Lee JC, Dubinett SM: Specific inhibition of cyclooxygenase 2 restores antitumor reactivity by altering the balance of IL-10 and IL-12 synthesis. J Immunol 2000, 164:361-370.

21. Sharma S, Yang SC, Zhu L, Reckamp K, Gardner B, Baratelli F, Huang M, Batra RK, Dubinett SM: Tumor cyclooxygenase-2/prostaglandin E2-dependent promotion of FOXP3 expression and $\mathrm{CD} 4+\mathrm{CD} 25+\mathrm{T}$ regulatory cell activities in lung cancer. Cancer Res 2005, 65:5211-5220.

22. Pold M, Zhu LX, Sharma S, Burdick MD, Lin Y, Lee PP, Pold A, Luo J, Krysan K, Dohadwala M, Mao JT, Batra RK, Strieter RM, Dubinett SM: Cyclooxygenase-2-dependent expression of angiogenic CXC chemokines ENA-78/CXC Ligand (CXCL) 5 and interleukin-8/CXCL8 in human nonsmall cell lung cancer. Cancer Res 2004, 64:1853-1860.

23. Pai R, Soreghan B, Szabo IL, Pavelka M, Baatar D, Tarnawski AS: Prostaglandin E2 transactivates EGF receptor: a novel mechanism for promoting colon cancer growth and gastrointestinal hypertrophy. Nat Med 2002, 8:289-293.

24. Dohadwala M, Batra RK, Luo J, Lin Y, Krysan K, Pold M, Sharma S, Dubinett SM: Autocrine/paracrine prostaglandin E2 production by non-small cell lung cancer cells regulates matrix metalloproteinase- 2 and CD44 in cyclooxygenase-2-dependent invasion. J Biol Chem 2002, 277:50828-50833.

25. Li S, Ma X, Ma L, Wang C, He Y, Yu Z: Effects of ectopic HER-2/neu gene expression on the COX-2/PGE2/P450arom signaling pathway in endometrial carcinoma cells: HER-2/neu gene expression in endometrial carcinoma cells. J Exp Clin Cancer Res 2013, 32:11.

26. Riedl K, Krysan K, Pold M, Dalwadi H, Heuze-Vourc'h N, Dohadwala M, Liu M, Cui X, Figlin R, Mao JT, Strieter R, Sharma S, Dubinett SM: Multifaceted roles of cyclooxygenase-2 in lung cancer. Drug Resist Updat 2004, 7:169-184.

27. Harris RE: Cyclooxygenase-2 (cox-2) and the inflammogenesis of cancer. Subcell Biochem 2007, 42:93-126.

28. Ghosh N, Chaki R, Mandal V, Mandal SC: COX-2 as a target for cancer chemotherapy. Pharmacol Rep 2010, 62:233-244.

29. Cathcart MC, O'Byrne KJ, Reynolds JV, O'Sullivan J, Pidgeon GP: COXderived prostanoid pathways in gastrointestinal cancer development and progression: novel targets for prevention and intervention. Biochim Biophys Acta 1825, 2012:49-63.

30. Steinbach G, Lynch PM, Phillips RK, Wallace MH, Hawk E, Gordon GB, Wakabayashi N, Saunders B, Shen Y, Fujimura T, Su LK, Levin B, Godio L, Patterson S, Rodriguez-Bigas MA, Jester SL, King KL, Schumacher M, Abbruzzese J, DuBois RN, Hittelman WN, Zimmerman S, Sherman JW, Kelloff $\mathrm{G}$ : The effect of celecoxib, a cyclooxygenase- 2 inhibitor, in familial adenomatous polyposis. N Engl J Med 2000, 342:1946-1952.

31. Heath El, Canto MI, Piantadosi S, Montgomery E, Weinstein WM, Herman JG, Dannenberg AJ, Yang WW, Shar AO, Hawk E, Forastiere AA: Secondary chemoprevention of Barrett's esophagus with celecoxib: results of a randomized trial. J Natl Cancer Inst 2007, 99:545-557.

32. Papadimitrakopoulou VA, William WN Jr, Dannenberg AJ, Lippman SM, Lee JJ, Ondrey FG, Peterson DE, Feng L, Atwell A, El-Naggar AK, Nathan CO, Helman JI, Du B, Yueh B, Boyle JO: Pilot randomized phase II study of celecoxib in oral premalignant lesions. Clin Cancer Res 2008, 14:2095-2101.

33. Dragovich T, Burris H 3rd, Loehrer P, Von Hoff DD, Chow S, Stratton S, Green S, Obregon Y, Alvarez I, Gordon M: Gemcitabine plus celecoxib in 
patients with advanced or metastatic pancreatic adenocarcinoma: results of a phase II trial. Am J Clin Oncol 2008, 31:157-162.

34. Edelman MJ, Watson D, Wang X, Morrison C, Kratzke RA, Jewell S, Hodgson L, Mauer AM, Gajra A, Masters GA, Bedor M, Vokes EE, Green MJ: Eicosanoid modulation in advanced lung cancer: cyclooxygenase-2 expression is a positive predictive factor for celecoxib + chemotherapy-Cancer and Leukemia Group B Trial 30203. J Clin Oncol 2008, 26:848-855.

35. Jakobsen A, Mortensen JP, Bisgaard C, Lindebjerg J, Rafaelsen SR, Bendtsen VO: A COX-2 inhibitor combined with chemoradiation of locally advanced rectal cancer: a phase II trial. Int J Colorectal Dis 2008, 23:251-255.

36. Mutter R, Lu B, Carbone DP, Csiki I, Moretti L, Johnson DH, Morrow JD, Sandler AB, Shyr Y, Ye F, Choy H: A phase II study of celecoxib in combination with paclitaxel, carboplatin, and radiotherapy for patients with inoperable stage IIIA/B non-small cell lung cancer. Clin Cancer Res 2009, 15:2158-2165.

37. Dohadwala M, Yang SC, Luo J, Sharma S, Batra RK, Huang M, Lin Y, Goodglick L, Krysan K, Fishbein MC, Hong L, Lai C, Cameron RB, Gemmill RM, Drabkin HA, Dubinett SM: Cyclooxygenase-2-dependent regulation of E-cadherin: prostaglandin E (2) induces transcriptional repressors ZEB1 and snail in non-small cell lung cancer. Cancer Res 2006, 66:5338-5345.

38. Noda M, Tatsumi Y, Tomizawa M, Takama T, Mitsufuji S, Sugihara H, Kashima K, Hattori T: Effects of etodolac, a selective cyclooxygenase-2 inhibitor, on the expression of E-cadherin-catenin complexes in gastrointestinal cell lines. J Gastroenterol 2002, 37:896-904.

39. Bozzo F, Bassignana A, Lazzarato L, Boschi D, Gasco A, Bocca C, Miglietta A: Novel nitro-oxy derivatives of celecoxib for the regulation of colon cancer cell growth. Chem Biol Interact 2009, 182:183-190.

40. Sitarz R, Leguit RJ, de Leng WW, Morsink FH, Polkowski WP, Maciejewski R, Offerhaus GJ, Milne AN: Cyclooxygenase-2 mediated regulation of E-cadherin occurs in conventional but not early-onset gastric cancer cell lines. Cell Oncol 2009, 31:475-485

41. Jang TJ, Cha WH, Lee KS: Reciprocal correlation between the expression of cyclooxygenase- 2 and E-cadherin in human bladder transitional cell carcinomas. Virchows Arch 2010, 457:319-328.

42. Okamoto A, Shirakawa T, Bito T, Shigemura K, Hamada K, Gotoh A, Fujisawa M, Kawabata M: Etodolac, a selective cyclooxygenase-2 inhibitor, induces upregulation of E-cadherin and has antitumor effect on human bladder cancer cells in vitro and in vivo. Urology 2008, 71:156-160.

43. Adhim Z, Matsuoka T, Bito T, Shigemura K, Lee KM, Kawabata M, Fujisawa M, Nibu K, Shirakawa T: In vitro and in vivo inhibitory effect of three Cox-2 inhibitors and epithelial-to-mesenchymal transition in human bladder cancer cell lines. Br J Cancer 2011, 105:393-402.

44. St John MA, Dohadwala M, Luo J, Wang G, Lee G, Shih H, Heinrich E, Krysan K, Walser T, Hazra S, Zhu L, Lai C, Abemayor E, Fishbein M, Elashoff DA Sharma S, Dubinett SM: Proinflammatory mediators upregulate snail in head and neck squamous cell carcinoma. Clin Cancer Res 2009, 15:6018-6027.

45. Segawa E, Kishimoto H, Takaoka K, Noguchi K, Hashitani S, Sakurai K, Urade $\mathrm{M}$ : Promotion of hematogenous metastatic potentials in human KB carcinoma cells with overexpression of cyclooxygenase-2. Oncol Rep 2010, 24:733-739.

46. Nakayama S, Sasaki A, Mese H, Alcalde RE, Tsuji T, Matsumura T: The E-cadherin gene is silenced by CPG methylation in human oral squamous cell carcinomas. Int J Cancer 2001, 9:667-673.

47. Maeda G, Chiba T, Okazaki M, Satoh T, Taya Y, Aoba T, Kato K, Kawashiri S, Imai K: Expression of SIP1 in oral squamous cell carcinomas: implications for E-cadherin expression and tumor progression. Int J Oncol 2005, 27:1535-1541.

48. Comijn J, Berx G, Vermassen P, Verschueren K, van Grunsven L, Bruyneel E, Mareel M, Huylebroeck D, van Roy F: The two-handed E box binding zinc finger protein SIP1 downregulates E-cadherin and induces invasion. $\mathrm{Mol}$ Cell 2001, 7:1267-1278.

49. Miyoshi A, Kitajima Y, Sumi K, Sato K, Hagiwara A, Koga Y, Miyazaki K: Snail and SIP1 increase cancer invasion by upregulating MMP family in hepatocellular carcinoma cells. Br J Cancer 2004, 90:1265-1273.

50. Tsubaki M, Komai M, Fujimoto S, Itoh T, Imano M, Sakamoto K, Shimaoka H, Takeda T, Ogawa N, Mashimo K, Fujiwara D, Mukai J, Sakaguchi K, Satou T, Nishida S: Activation of NF-kappaB by the RANKL/RANK system upregulates snail and twist expressions and induces epithelial-tomesenchymal transition in mammary tumor cell lines. J Exp Clin Cancer Res 2013, 32:62.
51. Hong KO, Kim JH, Hong JS, Yoon HJ, Lee Jl, Hong SP, Hong SD: Inhibition of Akt activity induces the mesenchymal-to-epithelial reverting transition with restoring $\mathrm{E}$-cadherin expression in $\mathrm{KB}$ and $\mathrm{KOSCC}-25 \mathrm{~B}$ oral squamous cell carcinoma cells. J Exp Clin Cancer Res 2009, 28:28.

52. Kinugasa $Y$, Hatori $M$, Ito H, Kurihara $Y$, Ito D, Nagumo M: Inhibition of cyclooxygenase-2 suppresses invasiveness of oral squamous cell carcinoma cell lines via down-regulation of matrix metalloproteinase-2 and CD44. Clin Exp Metastasis 2005, 21:737-745.

53. Kurihara $Y$, Hatori M, Ando $Y$, Ito D, Toyoshima T, Tanaka M, Shintani S: Inhibition of cyclooxygenase-2 suppresses the invasiveness of oral squamous cell carcinoma cell lines via down-regulation of matrix metalloproteinase-2 production and activation. Clin Exp Metastasis 2009, 26:425-432.

54. Kim YY, Lee EJ, Kim YK, Kim SM, Park JY, Myoung H, Kim MJ: Anti-cancer effects of celecoxib in head and neck carcinoma. Mol Cells 2010, 29:185-194.

55. Ko SH, Choi GJ, Lee JH, Han YA, Lim SJ, Kim SH: Differential effects of selective cyclooxygenase- 2 inhibitors in inhibiting proliferation and induction of apoptosis in oral squamous cell carcinoma. Oncol Rep 2008, 19:425-433.

56. Jang $\mathrm{TJ}$, Jeon $\mathrm{KH}$, Jung $\mathrm{KH}$ : Cyclooxygenase-2 expression is related to the epithelial-to-mesenchymal transition in human colon cancers. Yonsei Med J 2009, 50:818-824.

57. Shinohara M, Hiraki A, Ikebe T, Nakamura S, Kurahara S, Shirasuna K, Garrod DR: Immunohistochemical study of desmosomes in oral squamous cell carcinoma: correlation with cytokeratin and E-cadherin staining, and with tumour behaviour. J Pathol 1998, 184:369-381.

58. Takes RP, Baatenburg De Jong RJ, Alles MJ, Meeuwis CA, Marres HA, Knegt PP, De La Riviere GB, De Wilde PC, Mooi WJ, Hermans J, Van Krieken JH: Markers for nodal metastasis in head and neck squamous cell cancer. Arch Otolaryngol Head Neck Surg 2002, 128:512-518.

59. Tanaka N, Odajima T, Ogi K, Ikeda T, Satoh M: Expression of E-cadherin, alpha-catenin, and beta-catenin in the process of lymph node metastasis in oral squamous cell carcinoma. Br J Cancer 2003, 89:557-563.

60. Mandal M, Myers JN, Lippman SM, Johnson FM, Williams MD, Rayala S, Ohshiro K, Rosenthal DI, Weber RS, Gallick GE, El-Naggar AK: Epithelial to mesenchymal transition in head and neck squamous carcinoma: association of Src activation with E-cadherin down-regulation, vimentin expression, and aggressive tumor features. Cancer 2008, 112:2088-2100.

61. Bankfalvi A, Krassort M, Vegh A, Felszeghy E, Piffko J: Deranged expression of the E-cadherin/beta-catenin complex and the epidermal growth factor receptor in the clinical evolution and progression of oral squamous cell carcinomas. J Oral Pathol Med 2002, 31:450-457.

62. Mahomed F, Altini M, Meer S: Altered E-cadherin/beta-catenin expression in oral squamous carcinoma with and without nodal metastasis. Oral Dis 2007, 13:386-392.

63. Liu LK, Jiang XY, Zhou XX, Wang DM, Song XL, Jiang HB: Upregulation of vimentin and aberrant expression of E-cadherin/beta-catenin complex in oral squamous cell carcinomas: correlation with the clinicopathological features and patient outcome. Mod Pathol 2010, 23:213-224.

64. Pentenero M, Gandolfo S, Carrozzo M: Importance of tumor thickness and depth of invasion in nodal involvement and prognosis of oral squamous cell carcinoma: a review of the literature. Head Neck 2005, 27:1080-1091.

65. Lim SC, Zhang S, Ishii G, Endoh Y, Kodama K, Miyamoto S, Hayashi R, Ebihara S, Cho JS, Ochiai A: Predictive markers for late cervical metastasis in stage I and II invasive squamous cell carcinoma of the oral tongue. Clin Cancer Res 2004, 10:166-172.

66. Huber GF, Zullig L, Soltermann A, Roessle M, Graf N, Haerle SK, Studer G, Jochum W, Moch H, Stoeckli SJ: Down regulation of E-Cadherin (ECAD) a predictor for occult metastatic disease in sentinel node biopsy of early squamous cell carcinomas of the oral cavity and oropharynx. BMC Cancer 2011, 11(217):1-8.

\section{doi:10.1186/1756-9966-33-40}

Cite this article as: Fujii et al:: Restoration of E-cadherin expression by selective Cox-2 inhibition and the clinical relevance of the epithelial-tomesenchymal transition in head and neck squamous cell carcinoma. Journal of Experimental \& Clinical Cancer Research 2014 33:40. 